\title{
Sobre a semântica cognitiva e suas possíveis contribuições para a geração de paráfrases explanatórias em dicionários de tipo 2
}

\section{On Cognitive Semantics and its Possible Contributions to the Construction of Explanatory Paraphrases in Type-2 Dictionaries}

Larissa Moreira Brangel*

Universidade Federal do Rio Grande do Sul (UFRGS)

Porto Alegre - Rio Grande do Sul/Brasil

Félix Valentín Bugueño Miranda**

Universidade Federal do Rio Grande do Sul (UFRGS)

Porto Alegre - Rio Grande do Sul/Brasil

RESUMO: O presente artigo lança bases para a discussão a respeito das possíveis contribuiçóes da Semântica Cognitiva na geração de paráfrases explanatórias em dicionários de Tipo 2. Após uma análise da tipologia de dicionários escolares apresentada pelo MEC, foi concluído que os parâmetros estipulados por este órgão são muito vagos para que se tenha um modelo funcional de dicionário Tipo 2. Uma das grandes consequências desta carência de parâmetros é a falta de adequabilidade dos dicionários frente ao seu público alvo, especialmente no que diz respeito ao comentário semântico dos verbetes. Tendo em vista os diversos problemas verificados nas paráfrases explanatórias de três dicionários de Tipo 2 indicados pelo PNLD 2012 e baseando-se na ideia de que uma teoria da definição deve estar alicerçada em três variáveis, apontamos alguns aspectos da Semântica Cognitiva que podem ser úteis na concepção de definições voltadas para um público infantil.

PALAVRAS-CHAVE: lexicografia pedagógica; paráfrase explanatória; semântica cognitiva.

* larissabrangel@gmail.com

**felixv@uol.com.br 
ABSTRACT: This paper lays the foundations of a discussion about Cognitive Semantics' possible contributions to the writing of explanatory paraphrases on type- 2 dictionaries. After an evaluation of the pedagogical dictionary typology proposed by the Brazilian Ministry of Education, we concluded that the parameters stipulated then are too loose. So it is difficult for type-2-dictionary users to have a functional reference work. Such lack of trustful parameters entails a poor adequacy of the dictionaries concerning their users, especially in the semantic commentary field. Bearing in mind that the problems verified in the explanatory paraphrases of three type-2 dictionaries suggested by the National Textbook Program (PNLD), and accepting that a theory of lexicographic definition should be supported by three axioms, we suggest some Cognitive Semantic principles that could be useful to the conception of definitions proposed to children.

KEYWORDS: pedagogical lexicography; explanatory paraphrase; cognitive semantics.

\section{O dicionário como política educacional pública no Brasil}

Desde 2000, o Governo Federal brasileiro vem desenvolvendo um programa, chamado Programa Nacional do Livro Didático (PNLD), que visa a avaliar materiais didáticos, dentre eles os dicionários de língua portuguesa, com o objetivo de distribuir aos alunos da rede pública de ensino livros didáticos e dicionários que atendam um determinado patamar de qualidade.

No âmbito de avaliação dos dicionários, as várias ediçôes do PNLD têm resultado em editais que, sucessivamente, aprimoram os requisitos mínimos que as editoras devem cumprir para submeter as suas obras lexicográficas de referência à avaliação do Ministério da Educação. Comparese, por exemplo, os referenciais presentes nas licitações de 2005 e 2012.

\section{TABELA 1}

Parâmetros para o desenho de dicionários PNLD 2005

\begin{tabular}{|c|c|c|}
\hline $\begin{array}{l}\text { Tipos de } \\
\text { Dicionários }\end{array}$ & Etapa de Ensino & Caracterização \\
\hline Tipo 1 & $\begin{array}{l}1^{\circ} \text { e } 2^{\circ} \text { ano do } \\
\text { Ensino Fundamental }\end{array}$ & $\begin{array}{l}\text { - Mínimo de } 1.000 \text { e máximo de } 3.000 \text { verbetes } \\
\text {-Adequado à introdução das crianças a essa } \\
\text { espécie de obra }\end{array}$ \\
\hline Tipo 2 & $\begin{array}{l}3^{\circ} \text { e } 4^{\circ} \text { ano do } \\
\text { Ensino Fundamental }\end{array}$ & $\begin{array}{l}\text { - Mínimo de } 3.500 \text { e máximo de } 10.000 \text { verbetes } \\
\text {-Alunos em fase de consolidação do domínio } \\
\text { da escrita }\end{array}$ \\
\hline Tipo 3 & $\begin{array}{l}5^{\circ} \text { ano do Ensino } \\
\text { Fundamental até o final } \\
\text { do Ensino Médio }\end{array}$ & - Mínimo de 19.000 e máximo de 35.000 verbetes \\
\hline
\end{tabular}


TABELA 2

Parâmetros para o desenho de dicionários PNLD 2012

\begin{tabular}{|c|c|c|}
\hline $\begin{array}{l}\text { Tipos de } \\
\text { Dicionários }\end{array}$ & Etapa de Ensino & Caracterização \\
\hline Tipo 1 & $\begin{array}{l}1^{\circ} \text { ano do Ensino } \\
\text { Fundamental }\end{array}$ & $\begin{array}{l}\text { - Mínimo de } 500 \text { e máximo de } 1.000 \text { verbetes; } \\
\text { - Proposta lexicográfica adequada às demandas do } \\
\text { processo de alfabetização inicial. }\end{array}$ \\
\hline Tipo 2 & $\begin{array}{l}2^{\circ} \text { ao } 5^{\circ} \text { ano do Ensino } \\
\text { Fundamental }\end{array}$ & $\begin{array}{l}\text { - Mínimo de } 3.000 \text { e máximo de } 15.000 \text { verbetes; } \\
\text { - Proposta lexicográfica adequada a alunos em fase } \\
\text { de consolidação do domínio tanto da escrita } \\
\text { quanto da organização e da linguagem típicas } \\
\text { do gênero dicionário. }\end{array}$ \\
\hline Tipo 3 & $\begin{array}{l}6^{\circ} \text { ao } 9^{\circ} \text { ano do Ensino } \\
\text { Fundamental }\end{array}$ & $\begin{array}{l}\text { - Mínimo de } 19.000 \text { e máximo de } 35.000 \text { verbetes; } \\
\text { - Proposta lexicográfica orientada pelas } \\
\text { características de um dicionário padrão de uso } \\
\text { escolar, porém adequada a alunos dos últimos anos } \\
\text { do Ensino Fundamental. }\end{array}$ \\
\hline Tipo 4 & $\begin{array}{l}1^{\circ} \text { ao } 3^{\circ} \text { ano do Ensino } \\
\text { Médio }\end{array}$ & $\begin{array}{l}\text { - Mínimo de } 40.000 \text { e máximo de } 100.000 \text { verbetes; } \\
\text { - Proposta lexicográfica própria de um dicionário } \\
\text { padrão, porém adequada às demandas escolares do } \\
\text { Ensino Médio, inclusive o profissionalizante. }\end{array}$ \\
\hline
\end{tabular}

Ainda que seja possível reconhecer uma significativa melhoria nos requisitos mínimos que as obras devem cumprir, é possível perceber também que persiste uma inadequação entre o público-alvo ao qual os dicionários se destinam, as demandas curriculares e o desenho que, de fato, os dicionários apresentam. Para se obter maiores informações referentes às tarefas que os dicionários devem cumprir, na percepção da própria entidade que gesta a sua publicação, isto é, o Ministério da Educação, é necessário recorrer a fontes indiretas. Uma fonte útil de informaçôes são os documentos complementares ao próprio processo, intitulados Guia dos Livros Didáticos, e que aparecem paralelamente a cada edital. Há, portanto, edições desde o ano de 2007 até o ano de 2012. É curioso observar que é na análise que fazem as equipes do MEC às coleçôes de livros didáticos que se encontram observações que se podem empregar tanto para o desenho como para a avaliação de dicionários. Nesses textos, há referências que vão desde a necessidade de estimular o uso de dicionários, passando por informações que podem ser aproveitadas na definição dos componentes canônicos do dicionário, até informações referentes 
às tarefas linguísticas que o aluno das variadas séries deveria resolver com o auxílio de obras dicionarísticas. No entanto, é possível constatar também duas coisas: em primeiro lugar, não há um texto central que acolha o conjunto de parâmetros que deveria servir para o desenho (e posterior avaliação) dos diferentes "tipos de dicionários" (empregando a terminologia do PNLD) que o MEC deseja selecionar para o seu emprego na rede pública. Em segundo lugar, o fato de haver um Guia Didático que avalia e orienta os professores na escolha dos materiais bibliográficos para serem empregados na sala de aula não possui um equivalente em se tratando de dicionários. O efeito negativo é claro: por um lado, o desenho dos dicionários escolhidos pelo PNLD apresenta ainda resultados aquém do esperado; por outro, tampouco ajuda a uma discussão acadêmica que poderia levar a resultados aplicáveis à própria melhoria $\mathrm{e}$ qualificação das obras distribuídas pelo Ministério da Educação. Há, portanto, um hiato entre as necessidades do escolar brasileiro e o estado da arte da Metalexicografia.

\section{Os dicionários tipo 2 do PNLD e sua relação com a sua própria função e seus pretensos usuários}

Em Bugueño Miranda; Farias (2011), propõe-se que todo dicionário deveria resultar da relação harmônica entre seu enquadramento taxonômico, uma função pré-estabelecida para a obra lexicográfica e o estabelecimento de um perfil do pretenso usuário, segundo fica exposto na figura "ad infra":

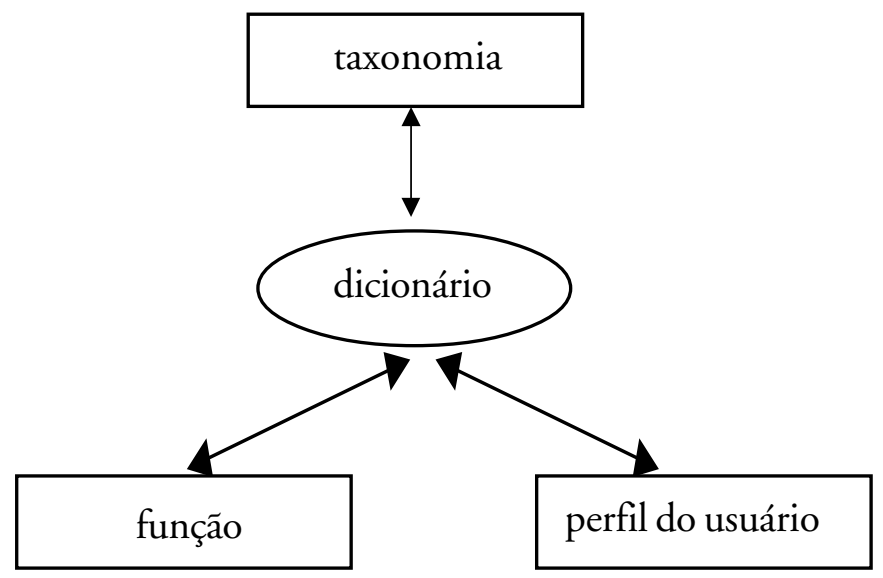

FIGURA 1 - Axiomas básicos para a concepção de uma obra lexicográfica 
Do ponto de vista taxonômico, um dicionário que almeja satisfazer as demandas de um indivíduo submetido a um processo de ensino-aprendizagem recebe o nome genérico de dicionário pedagógico. No caso dos dicionários destinados a nativos falantes, eles recebem o nome de dicionários escolares, embora Hartmann; James (2001, s.v. pedagogical dictionary) considere que essa nomenclatura não é apropriada. No entanto, não há, até o presente momento, uma terminologia melhor.

No âmbito dos dicionários escolares empregados no Brasil, trabalhos como os de Farias (2009), Pires (2012) e Selistre (2012) demonstram que, embora os dicionários empregados no ensino-aprendizagem se ajustem às exigências dos editais do PNLD, a qualidade dessas obras ainda fica aquém do esperado. O trabalho de Pires (2012), particularmente, demonstrou dois tipos específicos de problemas. Por um lado, não há, nas diretrizes para o ensino da língua materna das séries iniciais, um objetivo claro das habilidades linguísticas que os alunos do Ensino Fundamental devem desenvolver. De fato, é através de indícios indiretos, tais como as informações contidas nas sucessivas ediçôes dos guias dos livros didáticos, ou de instrumentos como a Provinha Brasil, que é possível inferir o que o MEC considera como objetivos a serem atingidos nas primeiras séries. Por outro lado, os critérios explicitados pelos editais como requisitos mínimos para as editoras submeterem suas obras à avaliação do MEC tampouco são completamente satisfatórios. No âmbito da definição macroestrutural quantitativa (BUGUEÑO MIRANDA, F. V; FARIAS, 2008), por exemplo, a densidade macroestrutural dos dicionários não está atrelada a nenhum parâmetro lexicométrico, como comprova, por exemplo, Farias (2009). Nessa mesma perspectiva, o trabalho de Pires (2012) prova que os dicionários Tipo 1, por exemplo, deveriam restringir o Programa Constante de Informações (PCI $)^{1}$ a dois segmentos informativos do comentário de forma, a saber, a forma ortográfica canônica e a divisão silábica, já que os alunos da $1^{\mathrm{a}}$ e $2^{\mathrm{a}}$ séries precisam de uma obra de referência idiomática que, basicamente, lhes possibilite confirmar as suas hipóteses ortográficas. Isto quer dizer, por exemplo, que uma criança em plena fase de alfabetização não precisa, prioritariamente, saber a significação de cachorro, mas sim como se escreve esta

\footnotetext{
${ }^{1}$ O Programa Constante de Informações constitui o número total de itens definidos para um verbete, e se divide em "comentário de forma" e "comentário semântico". Cada item corresponde a um "segmento informativo" (cf. BUGUEÑO MIRANDA, F. V; FARIAS (2006) e BUGUEÑO MIRANDA, F. V (2009) para esses conceitos).
} 
palavra. No que diz respeito aos dicionários Tipo 2, e ao se avaliar as referências contidas nas sucessivas edições do Guia de livros didáticos PNLD $(2007,2008$, 2010 e 2012), é possível constatar que o MEC atribui ao dicionário tarefas mais complexas que aquelas estabelecidas na Tabela 2 ("Parâmetros para o desenho do dicionário PNLD 2012"). O Edital se limita a oferecer a densidade macroestrutural e faz, além disso, uma alusão bastante genérica referente a que "a proposta lexicográfica [sc. deve ser] adequada a alunos em fase de consolidação do domínio tanto da escrita quanto da organização e da linguagem típica do gênero dicionário”. Note-se que há duas demandas diferenciadas. Por um lado, parece que o dicionário é concebido para ser um coadjuvante no processo do domínio completo da escrita (em termos de correção ortográfica? em termos de subsídios para a produção textual escrita?); por outro, o dicionário parece constituir um objeto de aprendizagem por si mesmo, na medida em que a sua consulta requer, de fato, uma habilidade específica. Nas edições do Guia do livro didático, por sua vez, descrevem-se atividades do livro didático referentes ao dicionário e que se poderiam sintetizar da seguinte maneira:

1) O dicionário constitui um tipo (gênero, na terminologia empregada pelo MEC) que requer um aprendizado e prática para o seu manuseio.

2) O dicionário deve ser empregado tanto para fins de recepção como para fins de produção textual

3) O dicionário deve permitir o ganho de massa léxica.

Em relação a esses objetivos, os trabalhos de Farias (2009) e Bugueño Miranda; Farias (2009) demonstram, por exemplo, que os dicionários escolares, assim como estão desenhados, não permitem cumprir satisfatoriamente com a função de produção textual. Por outro lado, no que diz respeito ao ganho de massa léxica, há, na literatura (por exemplo, BINON; VERLINDE, 2000, JACKSON, 2002, WELKER, 2006), referências a um genótipo lexicográfico, ${ }^{2}$ chamado de "dicionário de aprendizagem" ("vocabulary builder", na tradição lexicográfica anglo-saxônica) que tem por função permitir a aprendizagem de vocabulário. Esse genótipo é muito mais usado no ensino-aprendizagem de

${ }^{2}$ Genótipo lexicográfico é uma classe de dicionários que pode ser definida em termos de uma somatória de traços. Por outro lado, quando um dicionário demonstra possuir traços frouxos, corresponde a um fenótipo lexicográfico. Os genótipos lexicográficos se obtém como resultado da aplicação de uma classificação taxonômica de dicionários. 
uma língua estrangeira do que no ensino aprendizagem da língua materna. ${ }^{3}$ Dito em outros termos, se exige do dicionário escolar duas funções, auxílio à produção textual e ganho de massa léxica, que ele não tem condições de satisfazer. Em relação à tarefa de aprender a manuseá-lo, Bagno; Rangel (2006) oferecem já subsídios para desenvolver essa habilidade.

O objetivo do presente trabalho é avaliar em que medida os dicionários escolares do Tipo $2\left(2^{\circ}\right.$ ao $5^{\circ}$ ano do Ensino Fundamental $)$ permitem satisfazer uma das exigências feitas a eles, isto é, ajudar na elucidação do significado das palavras.

Para tanto, serão empregados os princípios da correlação entre definição taxonômica, função e perfil de usuário em relação ao dicionário, tal como exposto na Figura 1, assim como os princípios de uma teoria das paráfrases explanatórias.

\section{Semântica cognitiva e definição lexicográfica}

Conforme é preconizado por Bugueño Miranda (2009a), uma paráfrase explanatória deve estar alicerçada em três variáveis, a saber: uma taxonomia de paráfrases explanatórias, um pattern sintático e uma teoria semântica. Segundo o autor, enquanto a primeira variável está relacionada à escolha de um modelo parafrástico, a segunda está relacionada à formulação sintagmática da paráfrase e a terceira ao cálculo de informação da mesma. Neste primeiro momento, serão discutidos alguns aspectos referentes ao papel da Semântica Cognitiva como teoria semântica norteadora de paráfrases explanatórias em dicionários de Tipo 2.

A Semântica Cognitiva, teoria semântica proveniente da Linguística Cognitiva, teve suas origens no início da década de 1980, impulsionada, principalmente, pela publicação da obra Metaphors we live by. Nesta obra, Lakoff e Johnson (1980) procuram discutir aspectos sobre a função da metáfora como elemento organizador do sistema conceitual humano, ressaltando que a formação dos mapeamentos metafóricos, que ocorrem no nível da cognição, são amplamente influenciados pela experiência do homem no mundo em que vive.

A publicação da obra seminal de Lakoff e Johnson (1980) abriu espaço não apenas para o debate em torno da relação intrínseca entre mapeamentos metafóricos e a experiência do ser humano com o seu corpo e o com o

${ }^{3}$ De fato, para fins de aprendizagem de massa léxica da língua materna, só se pode citar o caso do MwebVocBder (1994). No âmbito do ensino de línguas estrangeiras, há muito mais expoentes, tais como o OxAmVocBder (2010) ou o Schümann (1993). 
ambiente no qual está inserido, mas também chamou a atenção para a grande influência que a fisiologia e a experiência humanas exercem na formação do sistema conceitual, que acaba sendo refletido na língua. Assim, nos últimos trinta anos, foi possível que defensores da proposta oferecida pela Semântica Cognitiva encontrassem nesta teoria subsídios para explicar outros fenômenos além da metáfora, tais como questōes pertinentes à metonímia (BARCELONA SÁNCHEZ, 2009), à categorização (LAKOFF, 1987; KLEIBER, 1990), à polissemia (GEERAERTS, 2001) e à aquisição da linguagem (TOMASELLO, 2003), para citar apenas alguns exemplos.

Uma revisão bibliográfica das áreas de aplicação da Semântica Cognitiva, no entanto, revela que têm-se dispensado pouca atenção às contribuiçōes que esta vertente teórica pode oferecer ao estudo dos dicionários. Dentre os autores de grande porte, podemos citar os trabalhos de Geeraerts (1997, 2001, 2003, 2006, 2007), que tem desenvolvido estudos fundamentados na concepção semântico-cognitiva da linguagem nas áreas de Lexicografia, Lexicologia e Semântica Lexical. Porém, com exceção deste autor, ainda são poucos os teóricos que se propõem a discutir aspectos referentes à Lexicografia com base nos postulados da Semântica Cognitiva. Ainda assim, é correto afirmar que os poucos trabalhos que procuraram abordar estas duas áreas mostraram resultados satisfatórios na discussão de problemas relativos à prática lexicográfica (OLIVEIRA, 2010; BRANGEL, L. M, 2011).Tendo em vista a atual situação dos estudos em Semântica Cognitiva e o potencial que esta abordagem apresenta para conduzir discussões no âmbito lexicográfico, é cabível se pensar nas possíveis contribuições que esta teoria semântica pode trazer para os dicionários de Tipo 2, tais como a aplicação da visão enciclopédica do significado ${ }^{4}$ na redação de uma paráfrase explanatória. Considerando que as políticas educacionais assumem que o instrumento lexicográfico utilizado nos primeiros anos de alfabetização deve ser uma obra diferenciada (RANGEL, 2011), mas que estas mesmas políticas ainda encontram dificuldades em delinear precisamente os fatores que tornariam uma obra de Tipo 2 ideal para o público infantil, acreditamos que a Semântica Cognitiva possa ser de grande valor para darmos os primeiros passos em direção à formulação de princípios orientadores para a compilação destas obras.

${ }^{4}$ Este conceito será apresentado e discutido mais adiante, na seção de número 5 do presente trabalho. 


\section{O comentário semântico}

Segundo Herbst e Klotz (2003, p. 170) um verbete corresponde à progressão thema-rhema; paralelamente, e no caso dos dicionários semasiológicos (nos quais se inclui o dicionário escolar) a progressão do verbete, em termos de informação sobre a unidade léxica, ocorre do significante ao significado. O conjunto total de informações referentes ao signo-lema se conhece como Programa Constante de Informações - PCI (BUGUEÑO MIRANDA, F. V.; FARIAS, 2011b), decupado em comentário de forma e comentário semântico. Cada item que compõe cada um dos comentários recebe o nome de "segmento informativo". Em relação ao comentário semântico, os segmentos informativos que o compõem são a paráfrase explanatória (BUGUEÑO MIRANDA, F. V, 2009a), as abonações e, quando pertinente, as substituições ostensivas (BRANGEL, L. M., 2011).

\subsection{A paráfrase}

Em relação à paráfrase explanatória, é pertinente assinalar, primeiramente, que o resultado da equação que constitui a "explicação sobre o signo-lema" depende de vários fatores: 1 ) a natureza do próprio signo-lema (a classe morfológica, o seu "potencial de explanação" - o que leva Farias (2008) a estabelecer a distinção entre paráfrases deficitárias e paráfrases opacas); 2) a teoria semântica empregada (BUGUEÑO MIRANDA, F. V.; FARIAS, 2011a); 3) a classe de dicionário em questão (produto de uma classificação de dicionários) em relação à função do dicionário e o perfil de usuário, segundo consta na Figura 1.

As paráfrases em dicionários de Tipo 2 representam uma série de desafios para o lexicógrafo. Em primeiro lugar, e seguindo os argumentos de Pires (2012), os dicionário para o ciclo anterior, os dicionários do Tipo 1, deveriam se concentrar em estimular, no estudante em fase de alfabetização, o descobrimento da heurística de como se organiza e como se consulta um dicionário. Em termos de tarefas a serem resolvidas pelo dicionário, os dicionários Tipo 1 deveriam servir exclusivamente para a comprovação ou refutação das hipóteses ortográficas do estudante em fase de consolidação da alfabetização. Já os dicionários de Tipo 2 , além das tarefas de comprovação ou refutação de hipóteses ortográficas, devem, sim, servir para a consulta sobre a significação das unidades léxicas. Isto supõe, por um lado, uma tarefa linguisticamente mais complexa; por outro, uma "estruturação" das paráfrases de forma que a informação contida nelas seja acessível à criança. Por 
estruturação, se entende, aqui, não somente as informações que permitem dar conta do conteúdo de uma unidade léxica, mas também a forma de apresentálas, assim como os eventuais mecanismos complementários de elucidação do significado. Em segundo lugar, é necessário levar em conta que toda paráfrase deve ser o resultado de uma taxonomia de paráfrases explanatórias, um pattern sintático e uma teoria semântica, como proposto em BUGUEÑO MIRANDA, F. V. (2009a). Em terceiro lugar, em BRANGEL, L. M.; BUGUEÑO MIRANDA, F. V. (2012) estabeleceu-se que, além do pattern sintático, o número de palavras que constituem a paráfrase é um parâmetro de formulação e avaliação que deve ser levado em conta, visto que o livro de língua portuguesa (para alfabetização) é o primeiro contato e exercício sistemático de leitura que a criança faz. Para estabelecer essa extensão, foi calculada uma média de palavras por frase desses livros. A média estabelecida resultou em treze palavras por frase.

Somando-se as considerações do parágrafo precedente, é evidente que o comentário semântico em dicionários Tipo 2 requer considerar não somente a formulação apropriada de paráfrases, o que já constitui um desafio per se, já que não há, na literatura, estudos sobre a sua formulação, mas deve-se levar em conta também outros segmentos informativos que possam vir a ter uma utilidade central. Nesse ponto, no entanto, é necessário fazer algumas ressalvas. Em primeiro lugar, o PCI de um dicionário Tipo 2 não pode ser extenso, ou seja, possuir muitos segmentos informativos. Por isso, opçōes tais como os póscomentários, ${ }^{5}$ que constituem uma possibilidade de acrescentar informação, estão descartadas a priori (FARIAS, 2011). Em segundo lugar, tampouco o PCI pode ser denso, ou seja, ser recursivo, o que quer dizer que um mesmo segmento informativo apareça dobrado, como acontece comumente, por exemplo, na lexicografia alemã (para os conceitos de "extensão" e "densidade" do PCI ver BUGUEÑO MIRANDA, F. V., 2009b, p. 62-64). ${ }^{6}$

\footnotetext{
${ }^{5}$ Em EGM (2011, s.v. esquilo) aparece a seguinte paráfrase explanatória, seguida de um pós-comentário: "animal mamífero pequeno e roedor, que tem a cauda longa e muito peluda, mora em árvores e se alimenta de nozes e sementes. Os esquilos brasileiros são chamados serelepes ou caxinguelês" (o destacado é nosso).

${ }^{6}$ Em EGM (2011, s.v.) encontramos um segmento informativo que identificamos primeiramente como sinonímia. No "Front matter", no entanto, não encontramos nenhuma informação referente à inclusão da sinonímia como segmento informativo, e tampouco a encontramos em outros verbetes onde era passível a presença desse fenômeno lexicológico. Tampouco há evidências que apontem para a sua inclusão com fins de produção textual (BUGUEÑO MIRANDA, F. V.; FARIAS, 2008) para
} 


\section{Semântica cognitiva}

Nesta seção, apresentaremos alguns princípios da Semântica Cognitiva, de modo a lançar bases para as possíveis contribuições que esta teoria semântica pode fornecer às paráfrases explanatórias em dicionários de Tipo 2 .

A teoria semântica ora apresentada encontra suas bases na Ciência Cognitiva, um estudo da mente e do seu processamento no qual são contempladas diferentes áreas do saber, tais como a Psicologia, a Filosofia, a Inteligência Artificial, a Neurociência, a Antropologia, a Sociologia, a Pedagogia e a Linguística. Foi o avanço dos estudos da Ciência Cognitiva (em especial da Psicologia Cognitiva) que, na década de 1970, propiciou um ambiente favorável para o surgimento de uma teoria linguística que estabelecesse uma relação entre cognição e linguagem nos moldes da Linguística Cognitiva, dando origem, assim, a esta disciplina. Partindo de uma visão panorâmica, Geeraerts e Cuyckens (2007, p. 5) definem a Linguística Cognitiva da seguinte maneira:

A Linguística Cognitiva é o estudo da linguagem na sua função cognitiva, onde cognitiva faz referência ao papel crucial das estruturas informacionais intermediárias em nossos encontros com o mundo. A Linguística Cognitiva é cognitiva no mesmo sentido que a Psicologia Cognitiva o é: por assumir que a nossa interação com o mundo é mediada por estruturas informacionais na mente. ${ }^{7}$

Lakoff (1990) define a Linguística Cognitiva em termos de dois compromissos primários, o Compromisso de Generalização [Generalization Commitment] e Compromisso Cognitivo [Cognitive Commitment]. Segundo o autor, o Compromisso da Generalização pode ser entendido como "o

a definição da sinonímia como segmento informativo com fins de produção textual). Dessa forma, concluímos que a sinonímia é empregada como um segmento informativo recursivo e complementar à paráfrase explanatória. Eis alguns exemplos: bosque "grande conjunto de árvores; mata, floresta"; madrinha "mulher que apresenta alguém para ser batizado ou crismado; dinda, dindinha"; rastro "marcas deixadas por animal ou pessoa no seu caminho; pegada".

7 [Cognitive Linguistics is the study of language in its cognitive function, where cognitive refers to the crucial role of intermediate informational structures in our encounters with the world. Cognitive linguistics is cognitive in the same way that cognitive psychology is: by assuming that our interaction with the world is mediated through informational structures in the mind.] 
compromisso em caracterizar os princípios gerais que regem os aspectos da linguagem humana"8 (LAKOFF, 1990, p. 40). O Compromisso Cognitivo, por sua vez, é definido como "um comprometimento em fazer com que uma perspectiva acerca da linguagem humana esteja em sintonia com o que já foi descoberto a respeito da mente e do cérebro, tanto em outras disciplinas como na nossa". ?

De uma forma geral, a Linguística Cognitiva pode ser dividida em duas grandes áreas de investigação, a Semântica Cognitiva, que tem como dois de seus principais expoentes o linguista George Lakoff e o filósofo Mark Johnson, e a Gramática Cognitiva (ou abordagens cognitivas à gramática) ${ }^{10}$ propagada, principalmente, pelas pesquisas dos linguistas Ronald Langacker e Leonard Talmy. Conforme foi explicitado, o enfoque do presente trabalho recairá sobre a Semântica Cognitiva.

Conforme sugere Riemer (2010, p. 238), a Semântica Cognitiva cobre uma grande gama de abordagens (EVANS; GREEN, 2006, GEERAERTS; CUYCKENS, 2007; LEE, 2001). Apesar de possuírem naturezas diversas, estas abordagens compartilham um importante ponto em comum, que corresponde a uma visão holística do lugar da linguagem dentro da cognição (RIEMER, 2010, p. 238). Para o autor, adotar a visão semântico-cognitiva da linguagem acarreta na aceitação de quatro princípios:

1) A rejeição a uma visão modular da linguagem;

2) A identificação do significado com a estrutura conceitual;

3) A rejeição da distinção entre sintaxe e semântica;

4) A rejeição da distinção entre semântica e pragmática.

Assim, o primeiro princípio remete ao Compromisso Cognitivo exposto por Lakoff (1990), uma vez que faz alusão à crença de que a língua seja governada pelos mesmos princípios cognitivos de outros domínios psicológicos, estabelecendo, assim, correlações entre os estudos da Semântica Cognitiva e outras áreas de investigação das Ciências Cognitivas. O segundo

\footnotetext{
${ }^{8}$ [a commitment to characterizing the general principles governing all aspects of human language.]

9 [A commitment to make one's account of human language accord with what is generally known about the mind and the brain, from other disciplines as well as our own.]

${ }^{10}$ No original, em Inglês, fala-se em cognitive (approaches) to grammar.
} 
princípio está relacionado à concepção enciclopédica do significado (em oposição à concepção linguística), que rejeita a distinção entre conhecimento dicionárístico e conhecimento enciclopédico. ${ }^{11}$ Nesta concepção, o estudo do significado linguístico se equipara ao estudo da natureza da estrutura conceitual humana, o que resulta em descrições mais abertas dos significados das palavras se comparadas às descrições com base em uma visão dicionarística. Mais adiante, retornaremos ao debate sobre a visão enciclopédica do significado, uma vez que entendemos este conceito como uma peça importante na discussão sobre definições lexicográficas. Os terceiro e quarto princípios, por sua vez, derivam, em certa medida, da concepção de língua como parte do sistema conceitual. Assim, conforme aponta Riemer (2010, p. 239), se a língua não é uma capacidade cognitiva distinta, as divisões internas da língua (como a semântica e a sintaxe e a semântica e a pragmática, por exemplo) também serão rejeitadas.

Outro aspecto pertinente diz respeito a duas terminologias que alicerçam a teoria semântica por ora delineada. Ao se enfocar o significado pela perspectiva da Semântica Cognitiva, dois conceitos-chave emergem: o experiencialismo [experientialism] e a corporeidade [embodiment]. Estes princípios, ao lado de conceitos tais como esquemacidade, perspectivação, saliência, protótipo, frames, esquemas de imagem, domínios, espaços mentais, dentre outros, ${ }^{12}$ conformam um conjunto de fundamentos que conduzem pesquisas não apenas na Semântica Cognitiva, mas na Linguística Cognitiva como um todo (ver GEERAERTS e CUYCKENS, 2007 para um maior detalhamento sobre

${ }^{11}$ Para estes dois conceitos, ver Evans e Green (2006, p. 206-244).

${ }^{12}$ Em sua obra dedicada a traçar um panorama da Linguística Cognitiva, desde seus conceitos básicos até as suas aplicações, Geeraerts e Cuyckens (2007) destinam a primeira parte do livro para apresentar os conceitos básicos desta teoria linguística. Fazem parte desta primeira seção os seguintes conceitos e abordagens: corporeidade e experiencialismo (ROHRER, 2007); Construal e perspectivação (VERHAGEN, 2007); schematicity (TUGGY, 2007); ancoragem conceitual, saliência e níveis básicos (SCHMID, 2007); polissemia, protótipos e categorias radiais (TOMASZCZYK 2007); frames, modelos cognitivos idealizados e domínios (CIENKI, 2007); metáfora (GRADY, 2007); esquemas de imagem (OAKLEY, 2007); metonímia (PANTHER; THORNBURG, 2007); attention phenomena (TALMY, 2007); força dinâmica (MULDER, 2007); semântica espacial (SLATEV, 2007); espaços mentais (FAUCONNIER, 2007); integração conceitual (TURNER, 2007) e iconicidade (LANGENDONCK, 2007) (alguns termos foram mantidos na sua língua de origem por não possuírem ainda uma tradução padrão para o português). 
estas pesquisas), dando sustentação ao Compromisso da Generalização proposto por Lakoff (1990).

Tanto o experiencialismo como a corporeidade derivam da Teoria da Cognição Corporificada [Embodied Cognition Thesis], que defende que

a natureza da organização conceitual emerge da experiência com o corpo, logo, parte do que faz com que a estrutura conceitual seja significativa é a experiência corpórea com a qual ela está associada. ${ }^{13}$ (EVANS; GREEN, 2006, p. 157).

É importante salientar que, apesar de aparecerem na literatura como dois termos distintos, a corporeidade e o experiencialismo geralmente coocorrem, uma vez que é através do corpo que o ser humano consolida a sua experiência no mundo. Por se tratar de dois fenômenos tão intrínsecos, é possível se falar em uma experiência corporificada para remeter aos termos corporeidade e experiencialismo de maneira concomitante. Os fenômenos estudados pela Semântica Cognitiva, portanto, serão sempre entendidos em função da maneira como o homem interage com o ambiente no qual está inserido, evocando os conceitos de experiencialismo e/ou corporeidade. ${ }^{14}$

As ideias defendidas pela teoria da cognição corporificada são amplamente debatidas por Lakoff e Johnson (1999, p. 3) ao tratarem da importância do corpo na formação de conceitos. Segundo os autores, três descobertas importantes na Ciência Cognitiva foram responsáveis por reabrir discussões filosóficas relativas à mente. São elas: 1) A mente é corporificada por natureza, 2) O pensamento é predominantemente inconsciente e 3) Os conceitos abstratos são, em grande medida, metafóricos. Na prática, os esquemas de imagem apresentados por Johnson (1987) constituem um bom exemplo da tese da cognição corporificada defendida pela Semântica

${ }^{13}$ [The nature of conceptual organisation arises from bodily experience, so part of what makes conceptual structure meaningful is the bodily experience with which it is associated.]

${ }^{14}$ Importante salientar que algumas abordagens podem estar fundamentadas mais em um conceito do que em outro, o que não ilegitima a importância destes dois conceitos para a Linguística Cognitiva. Conforme pode ser constatado em Lakoff (1993) e Lakoff e Johnson (1980), enquanto a Teoria da Metáfora Conceitual apresentada pela Semântica Cognitiva está fortemente ancorada no experiencialismo e na corporeidade, por exemplo, a Semântica de Frames, apresentada por Fillmore (2009), parece dedicar mais atenção ao experiencialismo para embasar seus postulados. 
Cognitiva. Johnson (1987, p. 19) define os esquemas de imagem como estruturas esquemáticas decorrentes de interações perceptuais e movimentos corpóreos, que possibilitam ao homem experienciar o mundo, entendê-lo e raciocinar sobre ele. Conforme é sintetizado por Evans e Green (2006, p. 158), "no modelo cognitivo, o conceito de esquema de imagem representa uma das maneiras pelas quais a experiência corpórea origina conceitos significativos". ${ }^{15}$

Em sua pesquisa sobre o papel da experiência corpórea na construção de conceitos, Johnson (1987, p. 28) apresenta uma série de esquemas de imagem que atuam constantemente na cognição humana, bem como as explicações para o seu surgimento. Tomemos, por ora, o esquema de imagem percurso como exemplo. Conforme assinala o autor, trata-se de um esquema de imagem constituído por três elementos (um ponto inicial A, um ponto final B e um vetor que traça uma trajetória entre os dois pontos) e uma relação (vista como um vetor que se move de A para B). Este esquema surge através de ações recorrentes no dia a dia do ser humano, tais como se deslocar de um lugar a outro ou lançar um objeto para alguém. A partir de situações mais concretas como essas, os esquemas de imagem são conceitualizados, de modo a serem utilizados também em situações mais abstratas, como a concepção (metafórica) da vida como um trajeto, em que nascemos (ponto A), vivemos (vetor de movimento) e morremos (ponto B). Este exemplo elucida um pouco a noção dos esquemas de imagem e a sua importância para o estudo do significado em Semântica Cognitiva, bem como a maneira pela qual o experiencialismo e a corporeidade se fazem presentes em nossas vidas na estruturação de conceitos.

Outro princípio fundamental da Semântica Cognitiva ao qual dispensamos especial atenção diz respeito à natureza enciclopédica do significado. Conforme exposto previamente, esta tese é decorrente do modo como a Semântica Cognitiva aborda o significado, ou seja, através da sua equiparação com a estrutura conceitual. Equiparar o significado à estrutura conceitual equivale a assumir que o conhecimento linguístico de um falante está estritamente relacionado ao conhecimento de mundo deste falante, uma vez que, nesta visão, a linguagem não se encontra em um módulo separado na mente, mas reflete uma grande parte da experiência humana (GEERAERTS, 2006, p. 10).

${ }^{15}$ [In the cognitive model, the image-schematic concept represents one of the ways in which bodily experience gives rise to meaningful concepts.] 
Evans e Green (2006, p. 215) apresentam uma distinção entre dois tipos de exploração do significado, conhecidos como visão dicionarística [dictionary view] e visão enciclopédica [encyclopedic view]. Segundo os autores, enquanto a visão dicionarística propõe um modelo que leve em conta o significado estritamente linguístico, a visão enciclopédica propõe um modelo que considere o sistema conceitual que, na ótica da Semântica Cognitiva, serve de sustentação para o significado linguístico. Este modelo enciclopédico, ao evocar fenômenos que vão além do domínio linguístico, vai ao encontro do Compromisso Cognitivo proposto por Lakoff (1990).

Uma das consequências de se adotar uma perspectiva enciclopédica é aceitar que a informação enciclopédica, na maioria dos casos, não assume a forma de conceitos únicos e bem delineados, mas é organizada em categorias amplas, as quais Geeraerts (2010, p. 222) caracteriza como "grandes blocos de conhecimento". Nas palavras do autor,

sabemos como assar panquecas, o que significa ir à biblioteca consultar um livro, como são as organizaçôes administrativas do nosso país, quando a Primeira Guerra Mundial começou e quando ela terminou - e todas estas formas de conhecimento transcendem as fronteiras de um item lexical. Uma concepção enciclopédica do significado linguístico, portanto, requer uma maneira de se representar estes grandes blocos de conhecimento juntamente com um meio de se relacionar os itens lexicais relevantes a esta ampla estrutura conceitual. (GEERAERTS, 2010, p. 222) ${ }^{16}$

Adotar uma concepção enciclopédica na definição de um item lexical, portanto, equivale a considerar uma gama de conhecimentos adjacentes a este item lexical. Definir uma banana nos moldes de uma visão enciclopédica da linguagem, por exemplo, ultrapassa falar sobre o seu pertencimento à classe das frutas, sua forma curvilínea e cor amarelada. Em uma visão enciclopédica da linguagem, definir uma banana pode evocar conhecimentos tais como a presença desta fruta em um determinado país, pratos típicos feitos a partir dela, seu aroma, gosto e consistência

\footnotetext{
${ }^{16}$ [We know how to bake pancakes, what it implies to go to the library to consult a book, what the administrative organization of our country looks like, when World War I started and when it ended-and all of these forms of knowledge far transcend the boundaries of a single lexical item. An encyclopedic conception of linguistic meaning, then, requires a way of representing those larger chunks of knowledge, together with a means of linking all the relevant lexical items to that broader conceptual structure.]
} 
característicos etc. Em decorrência disso, o conhecimento enciclopédico necessário para se definir uma banana pode mudar de acordo com o público ao qual a definição se dirige, uma vez que, conforme é sustentado por Fillmore (2009), os modelos mentais que estocam este conhecimento nem sempre são equivalentes.

É nesse sentido que a Semântica Cognitiva parece se apresentar como uma ferramenta útil para a geração de paráfrases explanatórias em dicionários de Tipo 2. Tendo em vista os consulentes do dicionário de Tipo 2 , ou seja, crianças que se encontram no primeiro ciclo do Ensino fundamental $\left(2^{\circ}\right.$ ao $5^{\circ}$ ano, conforme indica a proposta lexicográfica oferecida pelo MEC), acreditamos que uma teoria semântica que acolhe uma visão enciclopédica do significado esteja inclinada a fundamentar paráfrases explanatórias bastante acessíveis a estes consulentes. A conversão de alguns fundamentos da Semântica Cognitiva em princípios metodológicos para a geração de paráfrases explanatórias em dicionários de Tipo 2 representa, portanto, uma possibilidade de garantir a funcionalidade dos dicionários de Tipo 2 frente aos seus consulentes.

\section{Avaliação de paráfrases explanatórias de dicionários de tipo 2}

A análise conduzida a partir de agora tem como objetivo discutir alguns aspectos referentes à atual situação das paráfrases explanatórias de obras classificadas como dicionários de Tipo 2 pelo PNLD 2012. ${ }^{17}$ Para a presente análise, será utilizado o modelo de avaliação gerado por BRANGEL, L. M.; BUGUEÑO MIRANDA, F. V. (2012), que, baseado em um enquadramento taxonômico, um perfil de usuário e uma função do dicionário de Tipo 2, propõe os seguintes parâmetros avaliativos:

1) Categoria morfológica e suas particularidades: tendo em vista que os dicionários de Tipo 2 lematizam todas as categorias gramaticais da língua portuguesa e que estas categorias gramaticais são heterogêneas por natureza, é necessário que as análises dos verbetes levem em conta as propriedades características da classe de palavra sob enfoque.

2) O viés extensional da definição: tendo em vista o público alvo ao qual os dicionários de Tipo 2 se destinam, é necessário que as paráfrases explanatórias deste Tipo de obra prestem especial atenção ao seu viés extensional (quando assim houver), uma vez que esta dimensão da paráfrase pode assumir um papel essencial para o consulente na explicitação do significado do vocábulo a ser definido.

${ }^{17}$ A escolha das três obras avaliadas ocorreu de maneira aleatória. 
3) A sequência "paráfrase deficitária - segmentos informativos complementares": Farias (2008) estabelece que paráfrases explanatórias do tipo opacas podem ser de dois tipos: paráfrases opacas deficitárias (quando a opacidade da paráfrase ocorre em virtude da má formulação da mesma) e paráfrases opacas propriamente ditas (quando a paráfrase define uma unidade léxica cuja dificuldade de definição é intrínseca a esta unidade léxica). Neste segundo caso, a autora defende a necessidade de mecanismos complementares à paráfrase para que o consulente consiga ter acesso à significação das palavras. Em caso de paráfrases opacas propriamente ditas, procuraremos avaliar a adequabilidade dos exemplos e das ilustraçôes.

4) A distribuição das acepções nos verbetes: este fenômeno remete aos procedimentos conhecidos como Lumping [agrupamento] e Spliting [separação], nos quais o lexicógrafo opta por unir os significados em uma única acepção ou separá-los em distinções mais detalhadas (OLIVEIRA, 2010). Tanto o procedimento Lumping como o Splitting encontram vantagens e desvantagens em um dicionário de Tipo 2. O agrupamento de significados em uma única definição, por um lado, acarreta em um alto grau de abrangência ao verbete, conferindo uma microestrutura mais enxuta à obra lexicográfica. Este procedimento, por outro lado, pode resultar em definições muito amplas, resultando, assim, em paráfrases pouco esclarecedoras ao consulente. Em contrapartida, a técnica de separação de significados potencialmente apresentaria mais detalhamento nas acepçóes, dando uma maior quantidade de informação ao verbete. Conforme preconiza o MEC, os dicionários de Tipo 2 devem funcionar como instrumentos de elucidação de significados para estudantes do primeiro e segundo ciclos do Ensino Fundamental, logo, acreditamos que a recorrência à separação das acepções (Splitting) esteja em maior consonância com a função da obra.

5) O pattern sintático (extensão do enunciado): embora seja muito cedo para precisar o tamanho ideal de uma definição em um dicionário de Tipo 2, já é possível afirmar de antemão que as obras lexicográficas por ora avaliadas devem ser pensadas para um consulente que ainda se encontra no período de alfabetização e consolidação da leitura/escrita, o que nos leva a acreditar que sentenças longas (com grande quantidade de palavras) não contribuem para a interpretação do aluno. A fim de estabelecer um número padrão de palavras que devem conformar as frases interpretadas pelo nosso potencial consulente, calculamos a média de palavras presentes em sentenças extraídas aleatoriamente de três livros didáticos (SARGENTIM; FERNANDEZ, 1996, PETRY, 2006, CARPANEDA; BRAGANÇA, 2008) utilizados no segundo, terceiro e quarto ano do Ensino Fundamental. O resultado deste cálculo informou uma média de 12,43 palavras 
por frase, o que nos permite estabelecer que uma paráfrase explanatória de Tipo 2 não deve exceder o limite de 13 palavras em sua formulação sintática.

6) O pattern léxico (adequabilidade e lematização das palavras contidas nas definições): pelos mesmos motivos acima mencionados, é necessário que as palavras utilizadas na formulação das definições sejam de fácil acesso ao consulente do dicionário, que ainda possui um acervo lexical bastante limitado em comparação a um adulto. É, também, imprescindível que as palavras utilizadas nas definições estejam lematizadas no dicionário, para que o consulente possa ter autonomia de pesquisar palavras por ele desconhecidas caso se depare com alguma em uma definição.

\section{QUADRO 1}

Avaliação de paráfrases explanatórias de dicionários Tipo 2

\begin{tabular}{|c|c|c|c|}
\hline & AUIL (2008) & DIJR (2005) & SAJR (2010) \\
\hline Feijāo & $\begin{array}{l}\text { 1. Semente comestível do } \\
\text { feijoeiro. 2. Feijoeiro: } \\
\text { plantei muito pés de feijão. } \\
\text { 3. O feijão (1) cozido, } \\
\text { usado como alimento: } \\
\text { Como feijão e arroz todos } \\
\text { os dias. } 4 \text {. Qualquer } \\
\text { alimento: Não é rico mas } \\
\text { em suas casa não falta feijāo. }\end{array}$ & $\begin{array}{l}\text { 1. Semente do feijoeiro } \\
\text { - O Brasil é um grande } \\
\text { produtor de feijäo. } \\
\text { 2. Comida feita com essas } \\
\text { sementes - Os brasileiros } \\
\text { apreciam muito feijāo } \\
\text { com arroz. 3. Feijoeiro - } \\
\text { o feijão é uma planta com } \\
\text { muitas espécies. }\end{array}$ & $\begin{array}{l}\text { Semente do feijoeiro, } \\
\text { comestível e muito comum } \\
\text { no Brasil (Na fazenda, eram } \\
\text { plantados vários tipo de feijão: } \\
\text { feijāo-branco, feijāo-fradinho, } \\
\text { feijāo-preto e outros.). }\end{array}$ \\
\hline
\end{tabular}

Para discutirmos alguns aspectos do atual estado dos dicionários de Tipo 2, optamos por selecionar um substantivo concreto. Conforme apontam Bugueño Miranda; Beneduzi (2005, p. 119), a maior dificuldade em se definir este tipo de substantivo repousa na tentativa de definir o significado do vocábulo em vez de criar uma imagem do referente extralinguístico. ${ }^{18} \mathrm{O}$ vocábulo em questão diz respeito ao item lexical feijāo, um item lexical cuja dificuldade de definição é inerente à sua natureza. Por possuir esta característica intrínseca, as paráfrases explanatórias relativas a feijão serão sempre do tipo opacas propriamente ditas (FARIAS, 2008).

${ }^{18}$ Neste caso, é necessário salientar que o ideal é que a paráfrase ofereça ao consulente estes dois tipos de informação: a definição do significado e a imagem do referente extralinguístico. Em termos técnicos, podemos dizer que a definição do significado ocorre no nível da intensão da paráfrase, ao passo que o referencial extralinguístico ocorre no nível extensional. Por esta razão, a avaliação do viés extensional da paráfrase consta em nossa grade de avaliação. 
A dificuldade de se definir feijäo acarreta em diversos impasses para as obras lexicográficas, dentre os quais se encontram os problemas no viés extensional das definições. Assim, a análise das paráfrases extraídas de AuIl (2008), DiJr (2005) e SaJr (2010) deixa transparecer a dificuldade que estas obras encontram não apenas em informar ao consulente o significado de feijão, mas também em ajudá-lo a formar uma imagem mental que sirva de referência para este item lexical.

Em virtude da nossa experiência diária, é possível afirmar que o significado mais básico de feijāo, ou seja, o primeiro significado acessado pelos falantes do português brasileiro ao se depararem com este item lexical, está relacionado ao feijão cozido, servido no prato, tradicionalmente acompanhado de arroz. Uma maneira de se verificar esta hipótese é através da pesquisa do item lexical feijão em um site de busca na internet. ${ }^{19}$ Conforme observado, os resultados que mais se sobressaem na primeira página de busca da pesquisa fazem referência à concepção de feijão como alimento, através de receitas culinárias e dicas de nutricionistas envolvendo feijão. Este significado de feijāo como alimento é apresentado nas acepções de número 3 de Aull (2008) e 2 de (Dijr 2005) (SaJr não registra esta acepção do vocábulo). No entanto, apesar de se tratar de um significado importante para os falantes brasileiros, ele não parece ficar claro na leitura das paráfrases.

A complexidade ao ato de se definir feijāo sugere que seria necessário contar com mecanismos de apoio à definiçāo, tais como exemplos e ilustraçōes, para que o dicionário conseguisse cumprir com a sua função de informar ao consulente $o$ significado desta palavra. Nas obras analisadas, é possível perceber a utilização abundante de exemplos. Esta medida, embora correta, não assegura a eficiência da elucidação dos significados. Apesar de não possuirmos um instrumento que nos permita avaliar os exemplos através da utilização de critérios pré-estabelecidos, nos propomos a avaliar os mesmos com base nas possíveis contribuiçōes deste segmento à paráfrase precedente. Dentre os exemplos apresentados por AuIl (2008), acreditamos que apenas o exemplo referente à terceira acepção se coloque como uma complementação à paráfrase explanatória, uma vez que, ao evidenciar o arroz com um acompanhamento do feijão, oferece ao consulente uma informação relevante para o entendimento do significado de feijäo. O mesmo acontece com os exemplos oferecidos por $\mathrm{DiJr}$ (2005), dentre os quais acreditamos que apenas

${ }^{19}$ A consulta foi realizada no site de busca Google Brasil (www.google.com.br) no dia 28 de novembro de 2012. 
o exemplo relativo à acepção de número dois seja realmente funcional, pelo mesmo motivo que salientamos em AuIl (2008). SaJr (2010), no entanto, apresenta apenas uma definição de feijāo, e o exemplo complementar a esta definição não nos parece auxiliar na compreensão do significado da palavra.

Tendo em vista as diversas outras acepções que não parecem ter sido beneficiadas pelo uso dos exemplos (acepçôes 1, 2 e 4 de AuIl, 2008; 1 e 3 de DiJr, 2005 e a única acepção de SaJr, 2010), é necessário se pensar que outro tipo de complemento à paráfrase explanatória poderia auxiliar na elucidação do significado de feijāo. Neste caso, acreditamos que a utilização de imagens poderia ser um recurso bem explorado pelos dicionários. No entanto, apesar das três obras analisadas se apresentarem como obras do tipo ilustradas, nenhuma delas fornece uma imagem como recurso auxiliar às paráfrases de feijāo. Levando em conta que a unidade léxica feijāo suscita paráfrases opacas propriamente ditas e constitui um substantivo concreto que pode ser facilmente convertido em uma imagem, além de se tratar de um vocábulo bastante presente no dia a dia dos brasileiros, nos parece pertinente que as obras lexicográficas de Tipo 2 façam uso de imagens para auxiliar a definição deste item lexical.

Outro fator que merece ser observado é a heterogeneidade apresentada pelas obras em relação ao número de acepções de cada verbete. Enquanto AuIl (2008) expande os significados em quatro acepções, DiJr (2005) os apresenta em três acepções e SaJr (2010) os comprime em apenas uma acepção. A observância desta heterogeneidade no tratamento dos significados de feijäo demonstra que não parece existir um padrão estipulado para o tratamento das acepções em dicionários de Tipo 2. Nos PCN, é sugerido que o dicionário de Tipo 2 deve prover o consulente com informaçóes a respeito dos vários significados de uma palavra, o que nos levou a postular que a expansão dos significados seja a medida mais apropriada para este tipo de dicionários. Em nossa análise, no entanto, acreditamos que AuIl (2008), que apresenta o maior número de acepções, não seja a obra que melhor acertou no tratamento das acepçóes, uma vez que a acepção de número quatro, que apresenta feijāo como sinônimo de qualquer alimento, não parece necessária em um dicionário de Tipo $2 .{ }^{20}$

\footnotetext{
${ }^{20}$ Neste caso, a acepção do item lexical feijāo não se trata de um significado da palavra, e sim de uma expressão idiomática do português ("lá em casa nunca falta feijão"). O significado de feijāo como qualquer alimento, portanto, não parece ocorrer frequentemente no português, exceto na forma da expressão idiomática ora apresentada. Desta forma, não parece haver necessidade de uma acepção referente a este significado em um dicionário.
} 
Assim, Dijr (2005) parece ser a obra que melhor se enquadra às necessidades de seus consulentes, por apresentar, separadamente, o item lexical feijāo como sinônimo de a) a semente do feijoeiro, b) o alimento consumido pelos brasileiros e c) a planta também conhecida como feijoeiro.

A análise do pattern sintático e do pattern léxico se mostraram favoráveis aos padrões estipulados na nossa grade avaliativa. Conforme havíamos estipulado, o pattern sintático das paráfrases não deveria ultrapassar o limite de 13 palavras e este limite não foi estendido em nenhuma das paráfrases avaliadas. $\mathrm{Na}$ avaliação do pattern léxico, buscamos verificar se as palavras empregadas nas paráfrases explanatórias se encontravam lematizadas e definidas pelas obras lexicográficas, fato que também foi verificado nos três verbetes analisados. Importante salientar que esta última análise leva em conta apenas a presença ou ausência dos vocábulos na macroestrutura das obras, e não a funcionalidade destas definiçôes.

\section{Conclusões}

As discussōes conduzidas no presente artigo revelam alguns aspectos da atual situação da Lexicografia Pedagógica em solo brasileiro e permitem que se tracem algumas perspectivas para o debate nesta área. Nesse sentido, embora ainda não disponhamos de uma metodologia propriamente dita para a geração de paráfrases explanatórias sob a luz da Semântica Cognitiva, as consideraçōes levantadas conferem ao presente estudo um caráter prospectivo.

Diante da proposta lexicográfica apresentada pelas políticas públicas de educação (PNLD Dicionários) para o Ensino Fundamental, é possível inferir que o Ministério da Educação ainda não consegue especificar o que, de fato, é esperado de um dicionário de Tipo 2. Embora seja possível verificar uma constante melhoria nos sucessivos editais lançados pelo PNLD Dicionários nos últimos dez anos, os dicionários de Tipo 2 ainda carecem de um modelo efetivo que seja capaz de satisfazer os anseios de seus consulentes. Uma das consequências desta falta de especificidade de um desenho de dicionário de Tipo 2 são os fenótipos lexicográficos atualmente disponíveis no mercado e que compóem o acervo de obras lexicográficas indicadas pelo PNLD para alunos do $2^{\circ}$ ao $5^{\circ}$ ano do Ensino Fundamental. Estas obras, por não serem concebidas de acordo com uma taxonomia bem delineada, um perfil de usuário e uma função a qual devem cumprir, podem se revelar pouco funcionais para o seus consulentes, conforme pode ser verificado na análise das definiçōes do item lexical feijāo. 
O segundo tópico que merece atenção diz respeito a um problema que precede a falta de critérios do MEC e o problema de adequação das obras disponíveis no mercado. $\mathrm{O}$ tópico em questão está relacionado ao estado embrionário em que a pesquisa lexicográfica atualmente se encontra no Brasil. Assim, é possível afirmar que os dois problemas por ora verificados são decorrentes da carência de reflexão teórica a respeito da compilação de dicionários em nosso país. Restringindo o problema ao âmbito da definição lexicográfica e à geração de paráfrases explanatórias, é possível verificar que a literatura ainda não conta com uma teoria lexicográfica para a redação de paráfrases explanatórias (nem para dicionários gerais e tampouco para dicionários pedagógicos), embora alguns estudos já apontem que a utilização de uma teoria semântica na concepção de paráfrases explanatórias possa trazer boas contribuições a este segmento informativo.

Assim, diante do quadro exposto, cabe salientar que a Semântica Cognitiva parece se apresentar como uma ferramenta útil para a geração de paráfrases explanatórias voltadas para consulentes de dicionários de Tipo 2 . Conforme procuramos sugerir, os princípios apresentados por esta teoria semântica, como a visão enciclopédica do significado, demonstram um grande potencial para auxiliarem consulentes de séries iniciais do Ensino Fundamental ( $2^{\circ}$ ao $5^{\circ}$ ano) a compreenderem o significado de unidades léxicas fornecido pelas paráfrases explanatórias. O presente trabalho, portanto, se coloca como o passo inicial de uma grande empreitada, que consiste em descobrir um meio de transpor os princípios metodológicos da Semântica Cognitiva para a geração de paráfrases de dicionários de Tipo 2.

\section{Referências}

BAGNO, M.; RANGEL, E. de O. Dicionários em sala de aula. Brasília: MEC/ SEB, 2006.

BARCELONA SÁNCHEZ, A. O poder da metonímia. Cadernos de tradução, Porto Alegre n. 25, p. 7-24, 2009.

BINON, J.; VERLINDE, S. A contribuição da lexicografia pedagógica à aprendizagem e ao ensino de uma língua estrangeira ou segunda. In: LEFFA, V. J. (Org.). As Palavras e Sua Companhia. Pelotas: EDUCAT, 2000. p. 96-118.

BRANGEL, L. M. O tratamento lexicográfico de vocábulos de cores na perspectiva da Semântica Cognitiva. 2011. 209f. Dissertação (Mestrado em Letras) Instituto de Letras, UFRGS, Porto Alegre. 
BRANGEL, L. M., BUGUEÑO MIRANDA, F. V. Avaliação de paráfrases explanatórias de dicionários voltados para alunos em etapas iniciais de alfabetização. In: Anais do I simpósio Internacional de Lexicografia e Linguistica Contrastiva. Florianópolis, 2012. No prelo.

BUGUEÑO MIRANDA, F. V. Para uma taxonomia de paráfrases explanatórias. Alfa, São Paulo, v. 53, p.243-260, 2009a.

BUGUEÑO MIRANDA, F. V. Sobre a microestrutura em dicionários semasiológicos do alemão. Contigentia, Porto Alegre, v. 4, p. 60-72, 2009b. Disponível em: <http://hdl.handle.net/10183/20868>. Acesso em: 31 ago. 2010. BUGUEÑO MIRANDA, F. V.; FARIAS, V. S. Informações discretas e discriminantes no artigo léxico. Cadernos de Tradução, Florianópolis, n. 18, p. 115-135, 2006.

BUGUEÑO MIRANDA, F. V.; FARIAS, V. S. O ensino de português e os dicionários escolares: Um segmento informativo da microestrutura para fins de produção textual. Polifonia, Mato Grosso, v. 15, p. 1-14, 2008.

BUGUEÑO MIRANDA, F. V.; FARIAS, V. S. Panorama crítico dos dicionários escolares brasileiros. Lusorama, Frankfurt am Main, v. 77-78, p. 29-78, 2009.

BUGUEÑO MIRANDA, F. V.; FARIAS, V. S. Princípios para o desenvolvimento de uma teoria da definição lexicográfica. Alfa: Revista de Linguística, São José do Rio Preto, v. 55, p. 31-61, 2011 a.

BUGUEÑO MIRANDA, F. V.; FARIAS, V. S. Da microestrutura em dicionários semasiológicos do português e seus problemas. Estudos da Lingua(gem), v. 9, p. 39-69, 2011b

CIENKI, A. Frames, Idealized Cognitive Models, and Domains. In: GEERAERTS, D.; CUYCKENS, H. The Oxford handbook of Cognitive Linguistics. New York: OUP, 2007. p. 170-187.

Dijr. MATTOS, G. Dicionário Júnior da Língua Portuguesa. 3.ed. São Paulo: FTD, 2005.

EGM. Eu gosto mais: dicionário de alfabetização. São Paulo: IBEP, 2011.

EVANS, V.; GREEN, M. Cognitive Linguistics: an introduction. Edinburgh: Edinburgh University Press, 2006.

FARIAS, V. S. Desenho de um dicionário escolar de língua portuguesa. 2009. $285 \mathrm{f}$. Dissertação (Mestrado em Letras) - Instituto de Letras, UFRGS, Porto Alegre. 2009 FARIAS, V. S. Considerações preliminares sobre o pós-comentário na microestrutura de dicionários semasiológicos. Revista Virtual de Estudos da Linguagem, v. 9, p. 109-139, 2011. 
FAUCONNIER, G. Mental Spaces. In: GEERAERTS, D.; CUYCKENS, H. The Oxford handbook of Cognitive Linguistics. New York: OUP, 2007. p. 351-376.

FERREIRA, A. B. de H. Dicionário Aurélio Ilustrado. 1.ed. Curitiba: Positivo, 2008.

FILLMORE, C. Semântica de Frames. Cadernos de tradução, Porto Alegre, n. 25, p. 25-54, 2009.

GEERAERTS, D. Diachronic Prototype Semantics: a contribution to Historical Lexicology. Oxford: Claredon Press, 1997.

GEERAERTS, D. The definitional practice of dictionaries and the Cognitive Semantic conception of polysemy. Lexicographica, v. 17, p. 6-21, 2001.

GEERAERTS, D. Meaning and definition. In: STERKERBURG, Piet van. $A$ practical guide to lexicography. Amsterdam: John Benjamins, 2003.

GEERAERTS, D. Words and other wonders. Berlin: Mouton de Gruyter, 2006.

GEERAERTS, D. Introduction: a rough guide to Cognitive Linguistics. In: GEERAERTS, Dirk (Org.). Cognitive Linguistics: basic readings. Berlin: Mouton de Gruyter, 2006. p.1-28.

GEERAERTS, D. Lexicography. In: GEERAERTS, Dirk; CUYCKENS, Hubert. The Oxford handbook of Cognitive Linguistics. New York: OUP, 2007. p. $1160-1174$.

GEERAERTS, D.; CUYCKENS, H. The Oxford handbook of Cognitive Linguistics. New York: OUP, 2007.

GEERAERTS, D. Theories of Lexical Semantics. New York: Oxford University Press, 2010.

GRADY, J. Metaphor. In: GEERAERTS, D.; CUYCKENS, H. The Oxford handbook of Cognitive Linguistics. New York: OUP, 2007. p. 188-213.

HARTMANN, R. R. K.; JAMES, G. Dictionary of lexicography. London/New York: Routledge, 2001.

HERBST, T.; KLOTZ, M. Lexikographie. Paderborn: Schöningh, 2003.

JACKSON, H. Lexicography: an introduction. London: Routledge, 2002.

JOHNSON, M. The body in the mind: the bodily basis of meaning, imagination, and reason. Chicago: University of Chicago Press, 1987.

KLEIBER, G. La sémantique du prototype. Paris: Presses Universitaires de France, 1990.

LAKOFF, G. Women, fire, and dangerous things. What categories reveal about the mind. Chicago/London: The University of Chicago Press, 1987. 
LAKOFF, G. The invariance hypothesis: is abstract reason based on imageschemas? Cognitive Linguistics, n. 1, v. 1, p. 39-74, 1990.

LAKOFF, G. The contemporary theory of metaphor. In: ORTONY, A. (Ed.). Metaphor and Thought. 2. ed. Cambridge: Cambridge University Press, 1993. p. 202-251.

LAKOFF, G. JOHNSON, Mark. Metaphors we live by. Chicago: The University of Chicago Press, 1980.

LANGENDONCK, W. V. Iconicity. In: GEERAERTS, D.; CUYCKENS, H. The Oxford handbook of Cognitive Linguistics. New York: OUP, 2007. p.394-420. LEE, D. Cognitive Linguistics: an introduction. Nova York: Oxford University Press, 2001.

MwebVocBder. WOOD CORNOG, M. Merriam Webster's Vocabulary Builder. Springfield: Merriam-Webster Incorporated, 1994

MULDER, W. de. Force Dynamics. In: GEERAERTS, D.; CUYCKENS, H. The Oxford handbook of Cognitive Linguistics. New York: OUP, 2007. p. 294-317.

OAKLEY, T. Image Schemas. In: GEERAERTS, D.; CUYCKENS, H. The Oxford handbook of Cognitive Linguistics. New York: OUP, 2007. p. 214-235.

OLIVEIRA, A. F. S. de. Subsidios da Semântica cognitiva para a disposição das acepçôes nos learner's dictionaires. 2010. 232f. Dissertação (Mestrado em Letras) - Instituto de Letras, UFRGS, Porto Alegre.

OxAmVocBder. Oxford American Dictionary Vocabulary Builder. Oxford: Oxford University Press, 2010.

PANTHER, K.; THORNBURG, L. Metonymy. In: GEERAERTS, D.; CUYCKENS, H. The Oxford handbook of Cognitive Linguistics. New York: OUP, 2007. p. 236-263.

PIRES, J. A. Contribuiçôes para dicionários escolares destinados às séries iniciais. 2012. 150f. Dissertação (Mestrado em Letras) - Instituto de Letras, UFRGS, Porto Alegre.

RANGEL, E. de O. Dicionários escolares e políticas públicas em educação: a relevância da "proposta lexicográfica". In: CARVALHO, O. L. S.; BAGNO, M. (Org.). Dicionários escolares: políticas, formas e usos. São Paulo: Parábola, 2011. p. 37-60.

RIEMER, N. Introducing Semantics. New York: Cambridge University Press, 2010 .

ROHRER, T. Embodiment and Experientialism. In: GEERAERTS, D.; CUYCKENS, H. The Oxford handbook of Cognitive Linguistics. New York: OUP, 2007. p. 25-47. 
SARAIVA Júnior: Dicionário da Língua Portuguesa Ilustrado. 3. ed. São Paulo: Saraiva, 2010.

SCHMID, H. Entrenchment, Salience, and Basic Levels. In: GEERAERTS, D.; CUYCKENS, H. The Oxford handbook of Cognitive Linguistics. New York: OUP, 2007. p. 117-138.

SCHÜMANN, B. 500 Vokabeln zu Caesar: Ein Lernbuch. Hamburg: Buske, 1993

SELISTRE, I. C. T. Desenho de um dicionário passivo inglês/português para estudantes do ensino médio. 2012. 301f. Tese (Doutorado em Letras) - Instituto de Letras, UFRGS, Porto Alegre.

SLATEV, J. Spatial Semantics. In: GEERAERTS, D.; CUYCKENS, H. The Oxford handbook of Cognitive Linguistics. New York: OUP, 2007. p. 318-350.

TALMY, L. Attention Phenomena. In: GEERAERTS, D.; CUYCKENS, H. The Oxford handbook of Cognitive Linguistics. New York: OUP, 2007. p. 264-293.

TOMASELLO, M. Constructing a language: a usage-based theory of language acquisition. Cambridge: Harvard University Press, 2003.

TOMASZCZYK, B. L. Polysemy, Prototypes, and Radial Categories. In: GEERAERTS, D.; CUYCKENS, H. The Oxford handbook of Cognitive Linguistics. New York: OUP, 2007. p. 139-169.

TUGGY, D. Schematicity. In: GEERAERTS, D.; CUYCKENS, H. The Oxford handbook of Cognitive Linguistics. New York: OUP, 2007. p. 82-116.

TURNER, M. Conceptual Integration. In: GEERAERTS, D.; CUYCKENS, H. The Oxford handbook of Cognitive Linguistics. New York: OUP, 2007. p. 377393.

VERHAGEN, A. Construal and Perspectivization. In: GEERAERTS, D.; CUYCKENS, H. The Oxford handbook of Cognitive Linguistics. New York: OUP, 2007. p. 48-81.

WELKER, H. A. Dicionários. Uma pequena introdução à lexicografia. Brasília: Thesaurus, 2004. 